\title{
Assessing the prevalence of hepatitis B virus infection among health care workers in a referral hospital in Kisantu, Congo DR: a pilot study
}

\author{
Masaka Blandine LUNGOSI ${ }^{1}$, Basilua Andre MUZEMBO ${ }^{2 *}$, Nlombi Charles MBENDI ${ }^{1}$, \\ Natuhoyila Aliocha NKODILA ${ }^{1}$, Nlandu Roger NGATU ${ }^{2}$, Tomoko SUZUKI ${ }^{2}$, \\ Koji WADA $^{2}$, Nsukini Sebastien MBENDI ${ }^{1}$ and Shunya IKEDA ${ }^{2}$ \\ ${ }^{1}$ Gastroenterology Department, Faculty of Medicine, Kinshasa University, Congo DR \\ ${ }^{2}$ Department of Public Health, School of Medicine, International University of Health and Welfare, Japan \\ Received August 19, 2018 and accepted January 11, 2019 \\ Advanced Epub on J-STAGE January 23, 2019
}

\begin{abstract}
We aimed to determine hepatitis B virus (HBV) prevalence and risk factors for health care workers (HCWs) to contract HBV infection in a referral hospital in the Democratic Republic of Congo. From October 2015 to August 2016, we recruited 97 HCWs (55 males and 42 females, aged $41.2 \pm 10 \mathrm{yr}$ ) from Kisantu St. Luke's Hospital, a Congolese referral hospital located in the province of Kongo Central. Serum samples were assayed for HBV markers using ELISA. A questionnaire was used to record the HCWs' demographics, medical histories, and risk factors. The overall prevalence of exposure to $\mathrm{HBV}$ infection [HBsAg+, and/or hepatitis B core antibody (anti$\mathrm{HBc})+$ ] was $56.7 \%(55 / 97)$. HBsAg positivity was found in $18.6 \%(18 / 97)$ of the HCWs whereas $29.9 \%(29 / 97)$ were anti-HBc positive. Approximately $8.2 \%(8 / 97)$ of the $\mathrm{HCWs}$ tested positive for both HBsAg and anti-HBc. Being a physician [odds ratio (OR)=2.8 (95\% CI: 1.34-12.23)], a laboratory technician [OR=3.35 (95\% CI: 1.35-5.21)], and having multiple sex partners [OR=3.05 (95\% CI: 1.13-9.09)] were found to be factors associated with HBV infection. Exposure to HBV is common among HCWs at Kisantu St. Luke's Hospital. Isolated HBsAg was also prevalent among them. There is a high risk that HBV could be spread to others. Therefore, there is an urgent need for HBV screening, treatment, and vaccination policies.
\end{abstract}

Key words: Congo DR; Kisantu, Health care workers, Hepatitis B virus, Prevalence

Despite advances in hepatitis B virus (HBV) prevention and treatment, it remains a high-volume medical condition worldwide ${ }^{1)}$. HBV infection occurs everywhere, nonetheless, its prevalence is especially high in two World Health Organization (WHO) regions, namely the African and the Western Pacific Regions ${ }^{1)}$. These two WHO regions accounted for $60 \%$ of the 257 million affected individu-

*To whom correspondence should be addressed.

E-mail: andersonbasilua@yahoo.fr; muzembo_andre@iuhw.ac.jp

(C)2019 National Institute of Occupational Safety and Health als in $2015^{1)}$. Hepatitis B is one of the most devastating infectious diseases endemic in the Democratic Republic of Congo (Congo DR $)^{2}$. Notably, little attention has been paid to hepatitis related issues ${ }^{3}$. Hepatitis virus screening is not yet implemented routinely in the country, and the lack of adequate care and treatment programs make prevention of HBV infection an important topic. Nation-wide surveys are lacking, however, available evidence indicates that the prevalence of HBV surface antigen ( $\mathrm{HBsAg}$ ) carrier ranges between $4.9 \%^{2)}$ and $5.9 \%^{4)}$. This prevalence poses challenges not only to health care workers (HCWs) 
who are at risk of being infected through sharp objects and/or body fluids ${ }^{5}$, but also to patients because of the potential risk of transmission from HCW to patients ${ }^{6}$. This observation supports the necessity for HBV vaccination of individuals working in health care settings ${ }^{7)}$. In Congo $\mathrm{DR}$, the current prevalence of hepatitis B infection among HCWs is unknown. In addition, we could not find studies that have focused on HBV among HCWs in Congo DR to date. Most infected Congolese HCWs with HBV are unaware of their positive status because of limited access to affordable HBV screening tests and the low regard for viral hepatitis as compared to $\mathrm{HIV}^{8)}$. We aimed to carry out a pilot study to determine HBV prevalence, and risk factors for HCWs to contract HBV infection in a referral hospital. This pilot study provides insights in planning future studies, so as to help enhance advocacy for HCWs' vaccination against $\mathrm{HBV}$ in Congo DR.

The study followed the Helsinki Declaration and was approved by the Research Ethics Committee of the School of Public Health of Kinshasa University (reference number: ESP/CE/106/2015).

From October 1st, 2015 through August 2016, we used a cross-sectional design to carry out a hospital-based study at Kisantu St. Luke's Hospital (Hopital Saint Luc de Kisantu, HSLK), Kisantu, Kongo Central, Congo DR. Located in the western part of Congo DR, HSLK is a referral hospital and Kongo University teaching hospital. In 2015, HSLK employed 134 HCWs serving approximately 140,180 people with its 300 bed-capacity.

All HCWs ( $n=134)$ working in all departments were invited to participate in this study. The principal investigator approached them through the heads of departments. We did not use any predefined sampling strategy that would provide an epidemiologically valid representation of the HCWs at HSLK. The major inclusion criteria were being a registered HCW at HSLK and being present during the survey. The participation was voluntary and participants received a detailed overview of the survey prior to obtaining informed consent. After consent was obtained, the HCWs were invited to fill out a questionnaire and return it to the principal investigator within a month. The questionnaire gathered information on sociodemographics (including sex, age, marital status and work experience in the health sector), medical history (including blood transfusion history, liver disease history, HBV vaccination, consumption of intravenous/nasal illicit drugs, scarification, tattooing, piercing, surgery and occupational exposure to needlestick injury) and sexual behaviors. In addition, we collected blood for measurement of serologic markers of hepatitis B [HBsAg and hepatitis B core antibody (anti-HBc)]. Ten milliliters of blood was drawn from each $\mathrm{HCW}$ by a clinical laboratory technician from HSLK. Collected blood was centrifuged at $1,300 \mathrm{~g}$ for $10 \mathrm{~min}$ at $4^{\circ} \mathrm{C}$ to isolate serum. Isolated serum samples were aliquoted and stored temporarily at $-70^{\circ} \mathrm{C}$ for $24 \mathrm{~h}$. Then, samples were shipped to the virology department of Kinshasa University (Kinshasa, Congo DR) for analyses. HBsAg (Dialab-HBsAg ELISA Kit, Austria) and total anti-HBc (Dialab-HBc Ab ELISA Kit, Austria) were detected using enzyme-linked immunosorbent assay kits and results were expressed as positive or negative for HBsAg and anti-HBc.

Evidence of HBV exposure was considered as the presence of serum HBsAg and/or anti-HBc.

Test results were individually sent to the HCWs. Those who were positive for HBsAg were advised to consult research hepatologists [Masaka Blandine Lungosi (the first author), Nlombi Charles Mbendi (the third author), and Nsukini Sebastien Mbendi (the eighth author)].

The Statistical Package for the Social Sciences (SPSS) software version 21 (Chicago, IL, USA) was used for the analyses. Stata 14 software (StataCorp LP, College Station, TX, USA) was used for graphical illustration. Proportions and means were used to summarize categorical and continuous variables, respectively. Fisher's exact tests and student's $t$-test were used to compare differences between proportions and means, respectively. Logistic regression models were used for bivariate and multivariable analyses to determine odd ratios and $95 \%$ confidence intervals of the factors associated with HBV infection. The models were adjusted for age and gender.

Ninety-seven (72.4\%) of 134 eligible HCWs participated in the study (Table 1). Of them, none had been vaccinated against $\mathrm{HBV}$, and most of them $(92.8 \%$; 90/97) had a history of occupational exposure to blood during the last 12 months. HCWs in this study were likely to have multiple sex partners $(n=67 ; 69.8 \%)$ and not use a condom during sexual intercourse. HBsAg alone was isolated in $18.6 \%$ (18/97) of the HCWs and the detection rate was similar across genders; it was $9.3 \%(9 / 97)$ in male HCWs. The positivity rate for anti-HBc was $29.9 \%$ (29/97). About $8.2 \%(8 / 97)$ of the HCWs tested positive for both HBsAg and anti-HBc (Fig. 1). Most of the HCWs (56.7\%) had been exposed to HBV. The mean age of infected HCWs was lower compared to that in the non-infected. We also noted that most of the physicians and laboratory technicians had been exposed to HBV (Table 1).

As shown in Table 2, exposure to HBV was related to 
Table 1. Participants' characteristics by hepatitis B virus (HBV) infection status

\begin{tabular}{|c|c|c|c|c|}
\hline Variables & $\begin{array}{l}\text { All participants } \\
\qquad(\mathrm{n}=97)\end{array}$ & $\begin{array}{l}\text { Evidence of HBV exposure } \\
\qquad(\mathrm{n}=55)\end{array}$ & $\begin{array}{l}\text { No evidence of contact with HBV } \\
\qquad(\mathrm{n}=42)\end{array}$ & $p$-value $\Phi$ \\
\hline Age (yr) & $41.2 \pm 10.1$ & $39.0 \pm 9.5$ & $42.1 \pm 10.2$ & 0.004 \\
\hline$\leq 40$ & $49(50.5)$ & $32(58.2)$ & $17(40.5)$ & \\
\hline$>40$ & $48(49.5)$ & $23(41.8)$ & $25(59.5)$ & \\
\hline Sex & & & & 0.169 \\
\hline Male & $55(56.7)$ & $34(61.8)$ & $21(50.0)$ & \\
\hline Female & $42(43.3)$ & $21(38.2)$ & $21(50.0)$ & \\
\hline Marital status & & & & 0.192 \\
\hline Married & $68(70.1)$ & $41(74.5)$ & $27(64.3)$ & \\
\hline Unmarried & $29(29.9)$ & $14(25.5)$ & $15(35.7)$ & \\
\hline Work experience (yr) & & & & 0.129 \\
\hline$<30$ & $88(90.7)$ & $52(94.5)$ & $36(85.7)$ & \\
\hline$\geq 30$ & $9(9.3)$ & $3(5.5)$ & $6(14.3)$ & \\
\hline \multicolumn{5}{|l|}{ Profession } \\
\hline Physician & $9(9.3)$ & $7(12.7)$ & $2(4.8)$ & 0.016 \\
\hline Nurse & $63(64.9)$ & $37(67.3)$ & $26(61.9)$ & 0.368 \\
\hline Laboratory technician & $12(12.4)$ & $8(14.5)$ & $4(9.5)$ & 0.033 \\
\hline Other health workers* & $13(13.4)$ & $3(5.5)$ & $10(23.8)$ & 0.010 \\
\hline \multicolumn{5}{|l|}{ Medical history } \\
\hline Icterus & $6(6.2)$ & $4(7.3)$ & $2(4.8)$ & 0.474 \\
\hline Transfusion & $11(11.3)$ & $5(9.1)$ & $6(14.3)$ & 0.315 \\
\hline HBV infection & $1(1.0)$ & $1(1.8)$ & $0(0.0)$ & 0.567 \\
\hline Surgery & $51(52.6)$ & $25(45.5)$ & $26(61.9)$ & 0.080 \\
\hline Abortion & $15(36.6)$ & $7(33.3)$ & $8(40.0)$ & 0.453 \\
\hline Scarification & $18(18.6)$ & $6(10.9)$ & $12(28.6)$ & 0.026 \\
\hline Piercing & $1(2.4)$ & $1(4.8)$ & $0(0.0)$ & 0.500 \\
\hline Multiple sexual partners & $67(69.8)$ & $34(61.8)$ & $33(80.5)$ & 0.039 \\
\hline Use of condom & & & & 0.241 \\
\hline Never & $68(70.1)$ & $36(65.5)$ & $32(76.2)$ & \\
\hline Sometimes & $26(26.8)$ & $17(30.9)$ & $9(21.4)$ & \\
\hline Always & $2(2.1)$ & $2(3.6)$ & $0(0.0)$ & \\
\hline Illicit drug inhalation & $1(1.0)$ & $0(0.0)$ & $1(2.4)$ & 0.433 \\
\hline Alcohol consumption & $71(74.0)$ & $39(72.2)$ & $32(76.2)$ & 0.421 \\
\hline Needlestick injury & $90(92.8)$ & $50(90.9)$ & $40(95.2)$ & 0.344 \\
\hline Family history of icterus & $11(11.3)$ & $7(12.7)$ & $4(9.5)$ & 0.437 \\
\hline Family history of hepatitis B & $5(5.2)$ & $3(5.5)$ & $2(4.8)$ & 0.627 \\
\hline
\end{tabular}

ๆ $p$-values are comparing participants with "evidence of HBV exposure" to those with "no evidence of contact with HBV".

*Other health workers included workers at the sterilization unit, laundry service and housekeepers.

age. In the age and sex adjusted models, being a physician [odds ratio $(\mathrm{OR})=2.8(95 \% \mathrm{CI}: 1.34-12.23)$ ], a laboratory technician $[\mathrm{OR}=3.35$ (95\% CI: $1.35-5.21)]$, and having multiple sexual partnerships $[\mathrm{OR}=3.05(95 \% \mathrm{CI}$ : 1.13-9.09)] were associated with HBV infection.

This is the first study to assess the prevalence of HBV infection among HCWs in Congo DR. It provides a snapshot of the prevalence of HBV infection at HSLK. We found a high burden of HBV infection among HCWs, with an overall prevalence of HBsAg of $27.0 \%$ (HBsAg alone detected in $18.6 \%$ ) and an exposure to HBV of $56.7 \%$ (Fig. 1). We also found associations between HBV infection and being a physician, laboratory technician and having multiple sex partners. It was striking to observe that the percentage of detected HBsAg was high but none of the HCWs had a history of HBV vaccine uptake. This absence of HBV vaccination could be due to the lack of affordable HBV vaccines and vaccination policies. It is unfortunate because this high HBV prevalence can have dire consequences for both HCWs and patients. There may be an increased 


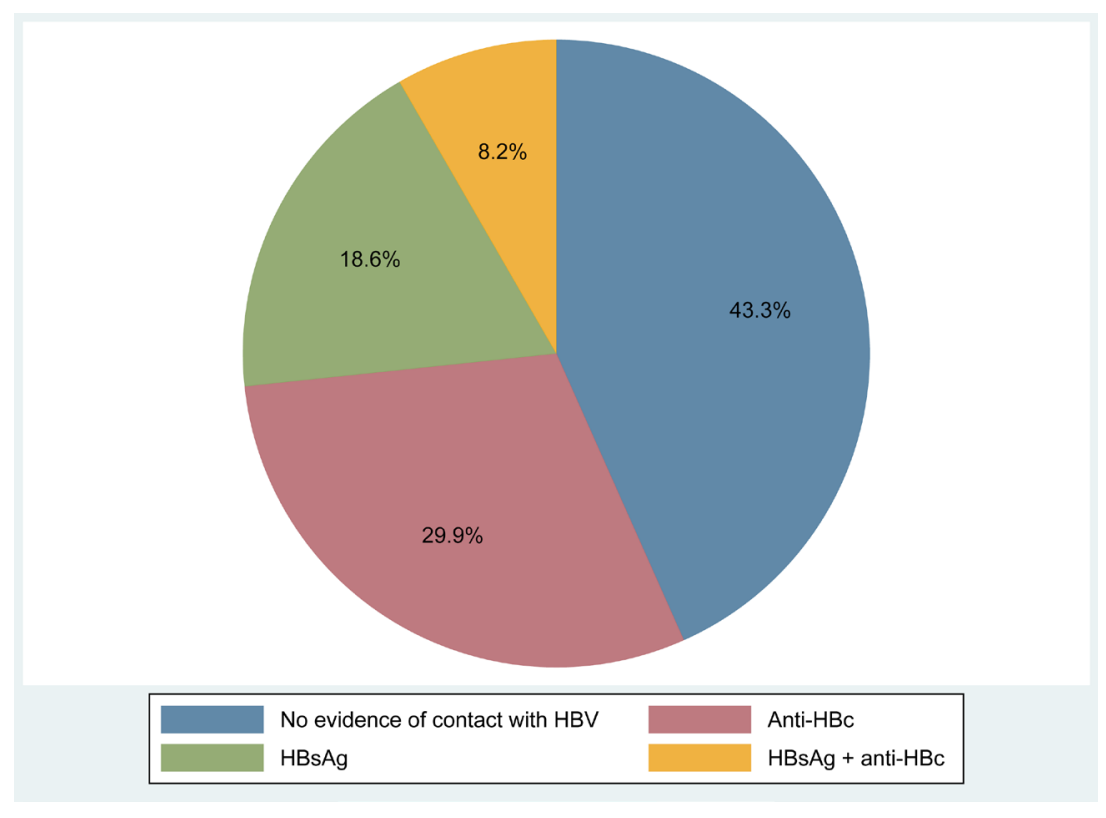

Fig. 1. Prevalence of serum hepatitis B virus (HBV) markers among healthcare workers (HCWs) at Kisantu St. Luke's Hospital (n=97). Among HCWs, evidence of HBV exposure, surface antigen of $\mathrm{HBV}$ (HBsAg), and hepatitis B core antibody (anti-HBc) were detected in $56.7 \%(55 / 97), 18.6 \%(18 / 97)$, and $29.9 \%$ (29/97), respectively. In addition, 8 (8.2\%) HCWs tested positive for both HBsAg and anti-HBc.

Table 2. Factors associated with exposure to hepatitis B virus (HBV) infection (n=97)

\begin{tabular}{|c|c|c|c|c|}
\hline \multirow{2}{*}{ Variables } & \multicolumn{2}{|c|}{ Unadjusted } & \multicolumn{2}{|r|}{ Adjusted } \\
\hline & $p$-value & OR $(95 \% \mathrm{CI})$ & $p$-value & OR $(95 \% \mathrm{CI})$ \\
\hline \multicolumn{5}{|l|}{ Sex } \\
\hline Male & & 1 & & 1 \\
\hline Female & 0.731 & $1.17(0.47-2.89)$ & 0.967 & $0.98(0.37-2.53)^{\oplus}$ \\
\hline \multicolumn{5}{|l|}{ Age (yr) } \\
\hline$<40$ & & 1 & & - \\
\hline$\geq 40$ & 0.006 & $2.46(1.90-4.63)$ & - & - \\
\hline \multicolumn{5}{|l|}{ Profession } \\
\hline Other & & 1 & & 1 \\
\hline Nurse & 0.583 & $1.26(0.55-2.93)$ & -- & -- \\
\hline Physician & 0.020 & $2.92(1.57-4.84)$ & 0.044 & $2.80(1.34-12.23)^{*}$ \\
\hline Laboratory technician & 0.046 & $2.62(1.45-5.78)$ & 0.026 & $3.35(1.35-5.21)^{*}$ \\
\hline \multicolumn{5}{|l|}{ Scarification } \\
\hline No & & 1 & & 1 \\
\hline Yes & 0.032 & $0.31(0.10-0.90)$ & 0.013 & $0.40(0.77-0.82)^{*}$ \\
\hline \multicolumn{5}{|l|}{ Multiple sex partners } \\
\hline No & & 1 & & 1 \\
\hline Yes & 0.002 & $2.55(1.82-6.67)$ & 0.007 & $3.05(1.13-9.09)^{*}$ \\
\hline
\end{tabular}


risk of hepatocellular carcinoma even when HBsAg is no longer detectable in the blood because HBV is susceptible to reactivation, especially in those with coinfection with $\mathrm{HIV}^{9}$. In addition, there is a potential risk of a patient acquiring an infection from HCWs. On the basis of these observations, we recommend a pre-vaccination screening approach of HCWs to detect those who might benefit from treatment or vaccination when it will be feasible in the country. One potential interpretation of our data indicating a high prevalence of HBV exposure in this population is that some of these HCWs could have been infected before working in the healthcare sector; i.e. during perinatal period or childhood. This is different from the USA where exposure to HBV mostly occurs in adulthood due to sexual intercourse ${ }^{10)}$. Alternatively, this high exposure to HBV and especially the high prevalence of HBsAg may suggest a possible ongoing risk of occupational exposure as accidents of exposure to blood were found to be relatively common (92.8\%) among HSLK's HCWs. This may not be unexpected as the Congolese healthcare system is currently facing several challenges. For example, a study conducted in Congo DR in 2009 found high rates of percutaneous injury among HCWs along with poor working conditions ${ }^{11)}$. In reference to profession, it was expected that exposure to HBV infection would be higher among nurses compared to physician because the latter is likely to have adequate knowledge about HBV transmission ${ }^{8)}$. In addition, occupational percutaneous injury is more common among nurses in Congo DR as compared to physicians ${ }^{11)}$. However, this was not found possibly due to the relatively small sample size of this study or the existence of additional routes of infection for physicians that may not be related to their occupation such as having multiple sex partners. A third interpretation for the high burden pertains to sexual intercourse. The reasons for this argument include the high exposure to $\mathrm{HBV}$ in HCWs who reported having multiple sex partners and unprotected sex.

The prevalence of HBV markers found in this study is somewhat similar or slightly higher to that found in previous studies that reported a higher burden of HBV infection among HCWs in Sub-Saharan Africa. For example, one study carried out in Niger in 2009 reported a prevalence of HBsAg of $15.3 \%$ among HCWs (versus $18.6 \%$ in this study ${ }^{12)}$, with the authors being doubtful of the priority of HBV vaccination in HCWs. Along this line, another study carried out in Senegal reported that $17.8 \%$ of HCWs tested positive for HBsAg (versus $18.6 \%$ in this study) ${ }^{13)}$. Furthermore, a study carried out in Uganda reported that $60.1 \%$ (versus $56.7 \%$ in this study) of the HCWs had evidence of $\mathrm{HBV}$ exposure, with $5.1 \%$ (versus $0 \%$ in this study) of the HCWs having a history of HBV vaccination ${ }^{14)}$. Ola and colleagues found that the prevalence of $\mathrm{HBV}$ infection was $65.9 \%$ in Nigerian $\mathrm{HCWs}^{15)}$. However, another recent study conducted in South Africa that had looked at occult HBV infections in $\mathrm{HCW}$ s found a relatively low prevalence of $\mathrm{HBV}$ markers ( $\mathrm{HBsAg}=2.9 \%$ and HBV DNA $=8.6 \%$ ), with $70.9 \%$ of the HCWs having a history of $\mathrm{HBV}$ vaccination ${ }^{16)}$. Although the routes of infection in these studies may be different, all these results suggest the need to protect HCWs in sub-Saharan Africa.

In this pilot study, only a few covariates were considered for the multivariable analysis. Hence, we may have missed identifying some risk factors associated with exposures to HBV at HSLK. In addition, not all markers of HBV infection could be measured because of the limited budget. Therefore, we were neither able to distinguish acute from chronic HBV infections, nor HCWs who were immune against HBV, or those who were still susceptible to HBV infection. Ideally, these limitations will be addressed in future research following resolution of logistic challenges.

Exposure to $\mathrm{HBV}$ is common among HCWs at Kisantu St. Luke's Hospital. There is a potential risk of spreading the virus to others. Therefore, there is an urgent need for HBV screening, treatment, and vaccination policies. This observation offers an insight to the epidemiology of HBV infection among Congolese HCWs. Our next step is to estimate the number of HCWs HBV carriers in Kongo Central, Congo DR.

\section{Funding}

None.

\section{Conflict of Interest}

We have no conflict of interest regarding this study.

\section{Acknowledgement}

The authors deeply thank all the participants of this study and HSLK administrative personnel.

\section{References}

1) World Health Organization (WHO) Global hepatitis report 2017. https://www.who.int/hepatitis/publications/globalhepatitis-report2017/en/. Accessed August 2, 2018. 
2) Shindano TA, Kabinda JM, Mitashi P, Horsmans Y (2018) Hepatitis B virus infection in the Democratic Republic of Congo: a systematic review of prevalence studies (2000 2016). J Public Health Berl. 26, 595. [CrossRef]

3) Muzembo BA, Akita T, Matsuoka T, Tanaka J (2016) Systematic review and meta-analysis of hepatitis $\mathrm{C}$ virus infection in the Democratic Republic of Congo. Public Health 139, 13-21. [Medline] [CrossRef]

4) Schweitzer A, Horn J, Mikolajczyk RT, Krause G, Ott JJ (2015) Estimations of worldwide prevalence of chronic hepatitis B virus infection: a systematic review of data published between 1965 and 2013. Lancet 386, 1546-55. [Medline] [CrossRef]

5) Auta A, Adewuyi EO, Tor-Anyiin A, Aziz D, Ogbole E, Ogbonna BO, Adeloye D (2017) Health-care workers' occupational exposures to body fluids in 21 countries in Africa: systematic review and meta-analysis. Bull World Health Organ 95, 831-841F. [Medline] [CrossRef]

6) Bhat M, Ghali P, Deschenes M, Wong P (2012) Hepatitis B and the infected health care worker: public safety at what cost? Can J Gastroenterol 26, 257-60. [Medline] [CrossRef]

7) Auta A, Adewuyi EO, Kureh GT, Onoviran N, Adeloye D (2018) Hepatitis B vaccination coverage among health-care workers in Africa: a systematic review and meta-analysis. Vaccine 3632 Pt B, 4851-60. [Medline] [CrossRef]

8) Shindano TA, Bahizire E, Fiasse R, Horsmans Y (2017) Knowledge, attitudes, and practices of health-care workers about viral hepatitis B and C in South Kivu. Am J Trop Med Hyg 96, 400-4. [Medline] [CrossRef]

9) Ioannou GN, Splan MF, Weiss NS, McDonald GB, Beretta L, Lee SP (2007) Incidence and predictors of hepatocellular carcinoma in patients with cirrhosis. Clin Gastroenterol Hepatol 5, 938-45, 945.e1-4. [Medline] [CrossRef]

10) Ioannou GN (2011) Hepatitis B virus in the United States: infection, exposure, and immunity rates in a nationally representative survey. Ann Intern Med 154, 319-28. [Medline] [CrossRef]

11) Ngatu NR, Phillips EK, Wembonyama OS, Hirota R, Kaunge NJ, Mbutshu LH, Perry J, Yoshikawa T, Jagger J, Suganuma N (2012) Practice of universal precautions and risk of occupational blood-borne viral infection among Congolese health care workers. Am J Infect Control 40, 68-70.e1. [Medline] [CrossRef]

12) Pellissier G, Yazdanpanah Y, Adehossi E, Tosini W, Madougou B, Ibrahima K, Lolom I, Legac S, Rouveix E, Champenois K, Rabaud C, Bouvet E (2012) Is universal HBV vaccination of healthcare workers a relevant strategy in developing endemic countries? The case of a university hospital in Niger. PLoS One 7, e44442. [Medline] [CrossRef]

13) Romieu I, Sow I, Lu S, Laroque G, Prince-David M, Romet-Lemonne JL (1989) Prevalence of hepatitis B markers among hospital workers in Senegal. J Med Virol 27, 282-7. [Medline] [CrossRef]

14) Braka F, Nanyunja M, Makumbi I, Mbabazi W, Kasasa S, Lewis RF (2006) Hepatitis B infection among health workers in Uganda: evidence of the need for health worker protection. Vaccine 24, 6930-7. [Medline] [CrossRef]

15) Ola SO, Odaibo GN, Olaleye OD, Ayoola EA (2012) Hepatitis B and E viral infections among Nigerian healthcare workers. Afr J Med Med Sci 41, 387-91. [Medline]

16) Sondlane TH, Mawela L, Razwiedani LL, Selabe SG, Lebelo RL, Rakgole JN, Mphahlele MJ, Dochez C, De Schryver A, Burnett RJ (2016) High prevalence of active and occult hepatitis B virus infections in healthcare workers from two provinces of South Africa. Vaccine 34, 3835-9. [Medline] [CrossRef] 